Systematic Review

\title{
G Does Percutaneous Vertebroplasty or Balloon Kyphoplasty for Osteoporotic Vertebral Compression Fractures Increase the Incidence of New Vertebral Fractures? A Meta-Analysis
}

\footnotetext{
Hui Zhang, MD, Caiyuan Xu, MD, Tongxing Zhang, MD, Zhongyu Gao, MD, PhD, and Tao Zhang, MD, PhD

From: Department of Anesthesiology, First Central Clinical College of Tianjin Medical University, Dept. of Orthopedic Surgery, Tianjin, China

Address Correspondence: Tao Zhang, MD, PhD First Central Clinical

College of Tianjin Medical University, Dept. of Orthopedic Surgery No. 24 FuKang Road NanKai District Tianjin, China E-mail: zht7o@sina.com

Conflict of interest: Each author certifies that he or she, or a member of

his or her immediate family, has no commercial association

(i.e., consultancies, stock ownership, equity interest, patent/licensing arrangements, etc.) that might pose a conflict of interest in connection with the submitted manuscript.

Manuscript received: 02-05-2015

Revised manuscript received: 06-02-2015 Accepted for publication: 08-11-2015

Free full manuscript: www. painphysicianjournal. com

Background: Because of an aging population,osteoporotic vertebral fractures are becoming more frequent. Conservative therapy was considered the gold standard for treating osteoporotic vertebra compression fractures (OVCFs) in the past. Percutaneous vertebroplasty (PVP) or balloon kyphoplasty (BKP) as minimally invasive techniques are new treatments that arewidely used for painful OVCFs. However an increase in new vertebral compression fractures at non-treated levels following augmentation is of concern. There is no convincing evidence that new fractures are inevitable after augmentation compared to after conservative treatment, and it is still unclear whether further fractures are the consequence of augmentation ora result of the natural progression of osteoporosis.

Objective: The objective of this study was to evaluate the new-level fracture risk after PVP or BKP compared with conservative (non-operative) treatment and to determine the dominant risk factor associated with new OVCFs.

Study Design: A meta-analysis of comparative studies was performed to evaluate the incidence of new vertebral fractures between vertebral augmentation, such as vertebroplasty and kyphoplasty, and no operation

Setting: The PubMed,ISI Web of Science, ELSEVIER ScienceDirect, and Cochrane Library databases and abstracts published in annual proceedings were systematically searched.In addition, we also retrieved data from references when titles met our inclusion criteria.

Methods: Detailed searches of a number of online databases comparing operative and non-operative groups were performed. We included randomized controlled trials, clinical controlled trials, and prospective clinical studies to provide available data. All studies were reviewed by 2 reviewers independently, and all the references that met our inclusion criteria were searched for additional trials, using the guidelines set by the QUOROM (Quality of Reporting of Meta-analysis) statement.

Results: We evaluated 12 studies encompassing 1,328 patients in total,including 768 who underwent operation with polymethylmethacrylateand 560 who received non-operative treatments. For new-level vertebral fractures, our meta-analysis found no significant difference between the 2 methods, including total new fractures $(P=0.55)$ and adjacent fractures $(P=0.5)$. For pre-existing vertebral fractures, there was no significant difference between the 2 groups (operative and non-operative groups) $(P=0.24)$ Additionally, there was no significant difference in bone mineral density, both in the lumbar $(P=0.13)$ and femoral neck regions $(P=0.37)$, between the 2 interventions.

Limitation: All studies we screened were published online except for unpublished articles. Moreover only a few data sources could be extracted from the published studies. There were only 5 randomized clinical trials and 7 prospective studies that met our inclusion criteria.

Conclusion: Vertebral augmentation techniques, such as vertebroplasty and kyphoplasty, have been widely used to treat osteoporotic vertebral fractures in order to alleviate back pain and correct the deformity, and it has been frequently reported that many new vertebral fractures occurred after this operation. Our analysis did not reveal evidence of an increased risk of fracture of vertebral bodies, especially those adjacent to the treated vertebrae, following augmentation with either method compared with conservative treatment.

Key words: Vertebroplasty, kyphoplasty, new osteoporotic compression vertebral fracture, meta-analysis

Pain Physician 2017; 20:E13-E28
} 
T he continued aging of the population around the world has aroused concern regarding osteoporosis and osteoporotic vertebral compression fractures (OVCFs). Conservative therapy such as bed rest, opioid analgesia, muscle relaxants, bracing, external fixation, and a combination of these treatments is routine. However, patients can become dissatisfied with long-term bed rest as it may cause various complications, such as pneumonia, urinary infection, bedsores, and deep venous thrombosis $(1,2)$, especially among the elderly. Conservative care can exacerbate bone demineralization, which inevitably increases the risk of bone fracture. Additionally, patients may have to tolerate the adverse effects of anti-inflammatory drugs and analgesics.

During the last few decades, 2 minimally invasive techniques for treating painful OVCFs, percutaneous vertebroplasty (PVP) and balloon kyphoplasty (BKP), have become widely used all over the world (3-8). Both procedures not only alleviate unbearable pain, but also stabilize the fractured vertebral body by injecting a small quantity of bone cement into the collapsed vertebral body $(3,7)$, and many authors have reported its advantages (9-15). However, bone cement injection can also cause many complications, such as cement leakage into the vertebral body, lungs, and veins, and new vertebral fractures can occur during follow-up after PVP $(4,16-23)$. Although vertebroplasty is increasingly used as a treatment for OVCFs, some authors have indicated that augmentation increases the risk for subsequent vertebral fractures (24-27), while others state that there is no explicit evidence that this procedure results in this poor outcomes (28-31). Additionally, some researchers have suggested that the procedure may actually reduce the incidence of adjacent level fractures (32). Furthermore, there are reports of this procedure being used for unalleviated pain at previously treated vertebral levels (33) and of the prophylactic use of vertebroplasty in non-fractured vertebrae at high risk for future fracture (34). However, controversy exists as to whether augmentation can increase the risk for new OVCFs during follow-up, and although there have been reported a number of clinical studies comparing PVP with conservative treatment $(27,28,30-32,35-41)$, including randomized controlled trials and prospective clinical studies, it remains unclear whether new fractures are due to this augmentation or simply are the result of the natural progression of osteoporosis. There are no data comparing PVP or BKP with conservative treatment to assess any increased risk of new fractures following treatment. Therefore, the purpose of this meta-analysis was to determine whether this procedure increased new-level vertebral fractures and whether vertebral fracture occurs adjacent to the treated one.

\section{Methods}

\section{Search Strategy}

In addition to the Cochrane Central Register of Controlled Trials, databases such as PubMed, ELSEVIER Science Direct, Web of Knowledge, and Embase were searched for articles on new fractures after vertebroplasty and kyphoplsty for painful OVCF. The search terms included "vertebroplasty" or "kyphoplasty" or "vertebral augmentation" and "new fracture" or "refracture" or "secondary fracture" or "subsequent fracture" and "conservative treatment" or "conservative therapy" or "optimal pain medication." Articles dated from January 1987 to October 2014 were downloaded and analyzed. No language restrictions were used in our search, and studies were selected with pre-prepared criteria; any divergence was resolved by agreement between the reviewers. Two reviewers independently searched all the titles, abstracts, and references to screen preliminarily the potential papers to be retrieved. When there was uncertainty, full-text articles were obtained.

\section{Selection of Studies}

Studies were selected for this meta-analysis if they met the following criteria: (1) comparative studies, including randomized and prospective clinical trials for treating OVCFs; (2) studies enrolling $\geq 30$ patients; all patients aged 50 years or older; back pain of no more than 12 months' duration; and bone marrow edema of vertebral fracture on magnetic resonance imaging (MRI) indicated a new fracture; and, (3) the fracture must be a painful OVCF between the T4-L5 level before treatment. The exclusion criteria were as follows: (1) the diagnosis of OVCFs was not clinically established (such as in patients with severe traumatic or cancerrelated vertebral fractures); (2) patients had untreatable coagulopathy; systemic or local spine infection, neurological deficits, or spinal stenosis; or concomitant hip fracture; (3) severe cardiopulmonary comorbidity; (4) case-control study, case report, retrospective study, systematic review, and meta-analysis; and (5) no relevant data could be extracted.

\section{Data Extraction}

All data extraction was done by the same 2 observ- 
ers independently for each study. Disagreement was solved by consensus. If no consensus was reached a third author was consulted. All included studies met the inclusion criteria and did not meet the exclusion criteria. The information contained common characteristics, such as publication year, authors, study design, intervention type, and improvement on the Visual Analogue Scale (VAS), physical functioning, and numbers of new vertebral fractures (total and adjacent to the treated vertebra).

\section{Statistical Analysis}

Statistical analyses were performed using Review Manager (RevMan, version 5.3, Copenhagen: The Nordic Cochrane Centre, The Cochrane Collaboration, 2011). Our meta-analysis was performed in strict accordance with the Cochrane Handbook for Systematic Reviews of Interventions 5.1.0 and 2009 Updated Method Guidelines for Systematic Reviews in the Cochrane Back Review Group (42). For dichotomous variables, we calculated the risk ratios (RRs) and 95\% confidence intervals (Cls) for each study while calculating mean differences (MDs) and $95 \% \mathrm{Cls}$ for the continuous variables, and a meta-analysis was performed on crude data extracted from the text. Statistical heterogeneity was assessed using 12 and chi-squared tests at a significance level of $P<0.05$. A fixed effects model was performed if there was no evidence of heterogeneity $(12<50 \%)$ among these studies, and if the evidence of heterogeneity was tested, a random effects model was replaced. In addition, a subgroup analysis allowed exploration of the influence of a variety of potential prognostic factors that might be associated with the outcome of the 2 treatments.

\section{Assessment of Methodological Quality}

Two of the reviewers independently assessed the methodological quality of the included studies in accordance with the Cochrane Handbook for Systematic Reviews of intervention, version 5.1.0 (42). We used a 7-item scale to assess the methodological quality of the studies included, which addressed the following issues: randomization sequence generation, allocation concealment, blinding of participants and personnel, blinding of outcome assessment, incomplete outcome data, and selective reporting.

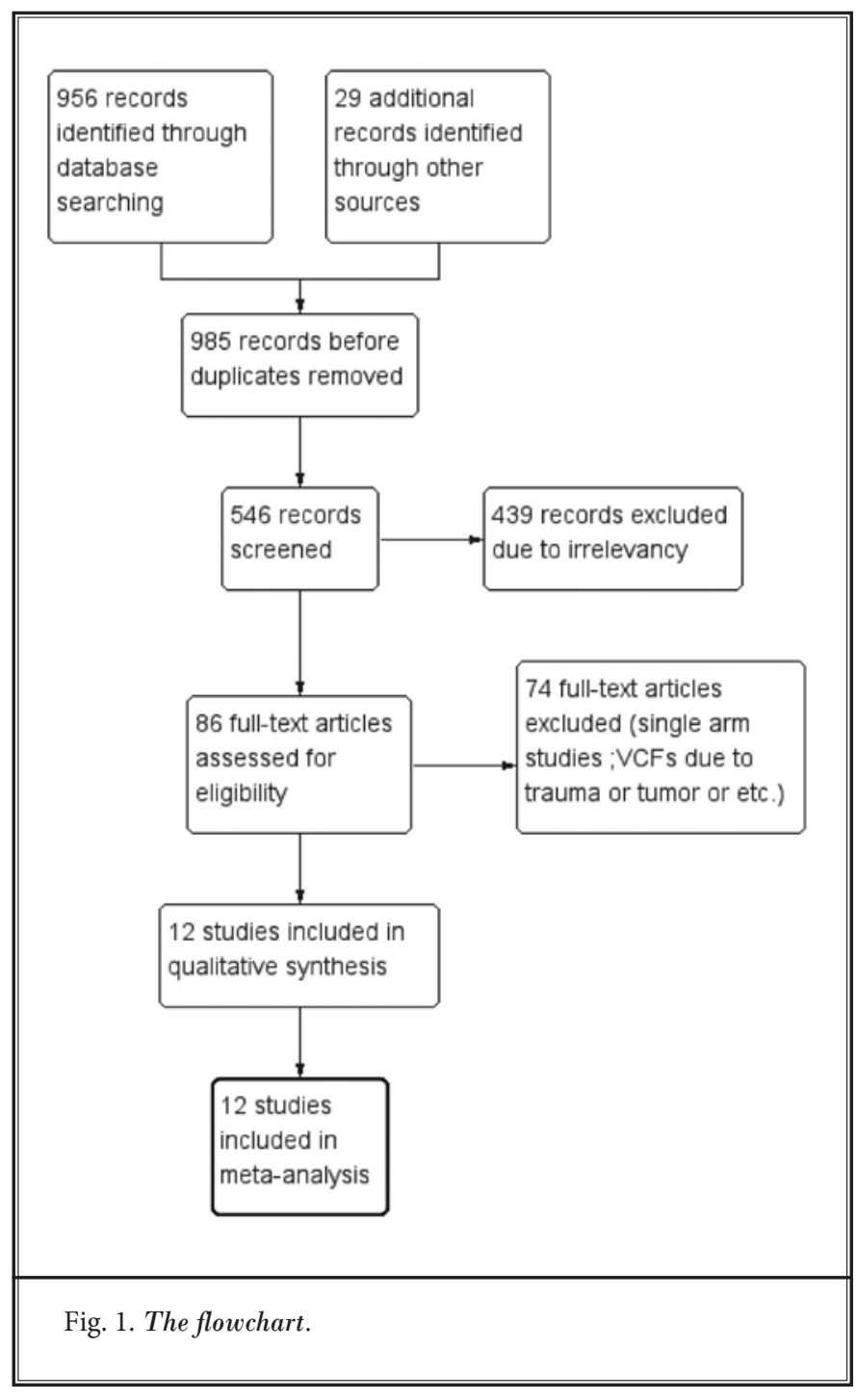

\section{Results}

\section{Search Results}

A total of 956 records were identified through online databases; after excluding duplicates and irrelevant articles, 86 full-text papers were assessed for eligibility. Finally, according to the inclusion criteria, 12 studies were assessed, including 5 randomized controlled trials $(27,38-41)$ and 7 prospective clinical controlled studies (28,30-32,35-37). The Quality of Reporting of Meta-analysis (QUOROM) flowchart illustrates the main reasons for trial exclusion (Fig. 1). The characteristics and the funnel plot of these studies are shown in Table 1 and Fig. 2. 
Pain Physician: January 2017: 20:E13-E28

Table 1. Demographic characteristics of the included studies.

\begin{tabular}{|c|c|c|c|c|c|c|c|c|c|c|}
\hline \multirow{2}{*}{ Study } & \multirow{2}{*}{ Year } & \multirow{2}{*}{$\begin{array}{l}\text { Study } \\
\text { design }\end{array}$} & \multicolumn{2}{|c|}{ Sample size } & \multicolumn{2}{|c|}{ Gender(F/M) } & \multicolumn{2}{|c|}{ Age(years) } & \multirow{2}{*}{ Follow-up } & \multirow{2}{*}{$\begin{array}{c}\text { Lost to } \\
\text { follow-up }\end{array}$} \\
\hline & & & PVP/BKP & CT & PVP/BK & $\mathbf{C T}$ & PVP/BKP & CT & & \\
\hline Kallmes & 2009 & RCT & 68 & 63 & $53 / 15$ & $46 / 17$ & $73.4 \pm 9.4$ & $74.3 \pm 9.6$ & 3 month & 6 \\
\hline Buchbinder & 2009 & RCT & 38 & 40 & $31 / 7$ & $31 / 9$ & $74.2 \pm 14$ & $78.9 \pm 9.5$ & 6 month & 6 \\
\hline Rousing & 2009 & RCT & 25 & 24 & $19 / 6$ & $21 / 3$ & $80(65-96)$ & $80(71-93)$ & 3 month & 3 \\
\hline Farrokhi & 2009 & RCT & 40 & 42 & $30 / 10$ & $30 / 12$ & $72(59-90)$ & $74(55-87)$ & 36 month & 6 \\
\hline Klazen & 2010 & RCT & 101 & 101 & $70 / 31$ & $70 / 31$ & $75.2 \pm 9.8$ & $75.4 \pm 8.4$ & 12 month & 25 \\
\hline Diamond & 2006 & Pro & 88 & 38 & $56 / 32$ & $31 / 7$ & $76.8 \pm 8.7$ & $76.1 \pm 10$ & 24 month & 7 \\
\hline Wang & 2010 & Pro & 32 & 23 & $27 / 5$ & $20 / 3$ & $72.9 \pm 12.4$ & $72.7 \pm 9.1$ & 12 month & NR \\
\hline Diamond & 2003 & Pro & 55 & 24 & $35 / 20$ & $20 / 4$ & $76.5 \pm 9.3$ & $76.3 \pm 10$ & 12 month & NL \\
\hline Alvarez & 2006 & Pro & 101 & 27 & $81 / 20$ & $22 / 5$ & $73.3 \pm 7.9$ & $69.7 \pm 7.7$ & 12 month & NR \\
\hline Voormolen & 2007 & Pro & 18 & 16 & $14 / 4$ & $14 / 2$ & $73(55-88)$ & $72(59-84)$ & 12 month & NR \\
\hline $\mathrm{Yi}$ & 2014 & Pro & 169 & 121 & $113 / 56$ & $68 / 53$ & $72 \pm 9.9$ & $66.7 \pm 14.9$ & $49.4(36-80)$ month & $\mathrm{NL}$ \\
\hline Movrin & 2012 & Pro & 46 & 61 & $36 / 10$ & $49 / 12$ & $67.8 \pm 5.4$ & $73.8 \pm 7.5$ & 12 month & $\mathrm{NL}$ \\
\hline
\end{tabular}

\section{Quality Assessment}

There were only 2 studies comparing vertebroplasty and a simulated vertebroplasty without cement $(38,40)$ in this meta-analysis, and 10 articles directly compared PVP or BKP with conservative treatment $(27,28,30$ $32,35-37,39,41)$. The methodological quality and risk of bias of the included studies is shown in Tables 2 and 3.

\section{New Vertebral Fractures}

All included studies reported total new vertebral fracture rates during follow-up, except for one paper (40). There were no significant differences between vertebroplasty and conservative treatment in the other 11 articles $(P=0.55)$. We also analyzed the incidence of new vertebral fractures adjacent to the treated one. We found that there was no statistically significant difference for new vertebral fractures adjacent to the treated one $(P=0.50)$. The score on a modified 23-item version of the Roland Morris Disability Questionnaire (RDQ) was evaluated after the 2 treatments for acute osteoporotic vertebral fractures. There was a significant difference in the RDQ less than one week later $(P=0.004)$, while a statistically significant difference was not obvious ( $P$ $=0.64$ ) one month later. Moreover, we calculated pain relief after the operative and non-operative therapies in different periods (Fig. 3-10).

A few potential risk factors associated with new vertebral fractures after different treatments were evaluated in this meta-analysis. They were as follows: (1) the total number of pre-existing osteoporotic ver- tebral fractures before a specific therapy; (2) the bone mineral density (BMD) of the lumbar or femoral neck; (3) the local kyphotic angle of the pretreated fracture vertebrae; (4) the severity of the fracture body; and (5) patients' ages and the proportion of women (Figs. 11-16).

\section{Discussion}

PVP and BKP have become more popular for treating OVCFs since the first cases of successful vertebral augmentation by intravertebral injection of polymethyl methacrylate (PMMA) in patients with vertebral hemangiomas was described by Galibert et al (43). It has been reported that PVP or BKP is better for relieving not only chronic but also acute pain due to OVCF $(4,44-$ 46). However, any new medical technology has certain complications and risks, and these techniques are not exceptions. For example, cement leakage, related complications, and new vertebral fractures after PVP or BKP during follow-up have been reported. Complications regarding new-level fractures have been reported in many retrospective studies, raising concern over whether it is possible that augmentation increases the incidence of new compression fractures, especially in adjacent vertebrae. Although its benefits have been demonstrated, there is debate about whether PVP also increases fracture rates by inducing or facilitating subsequent vertebral fractures. Many investigators attempted to explore this issue through both biomechanical and clinical studies in order to determine the 


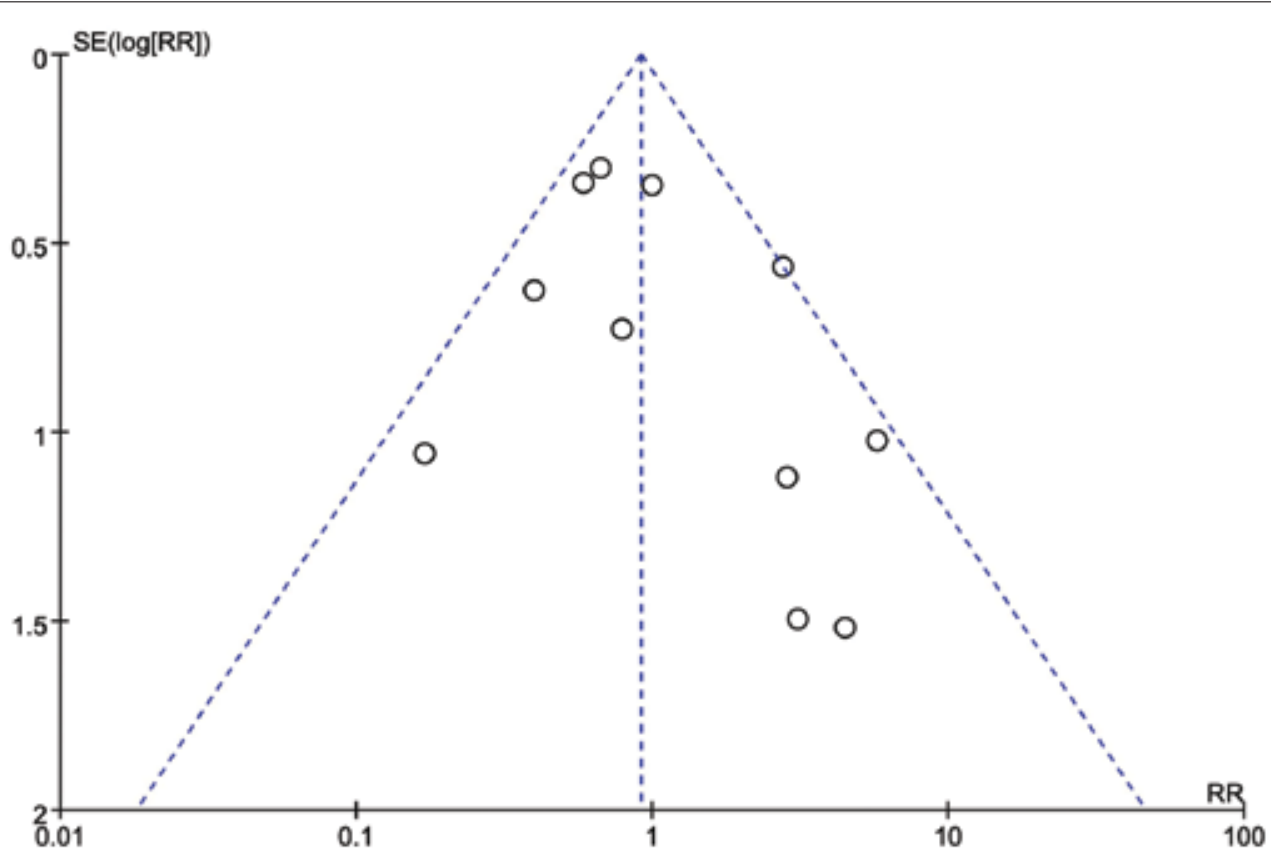

Fig. 2. Funnel plot for total number of new vertebral fracture between the 2 treatments.

Table 2. Assessment of methodological quality items presented as percentages across all included studies.

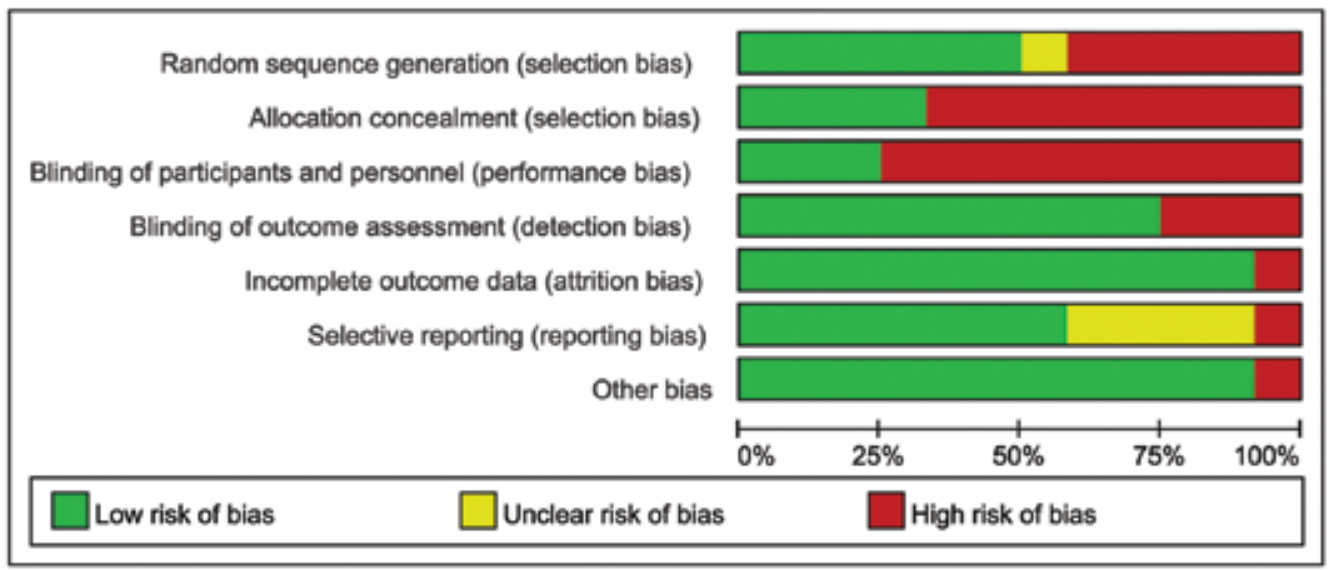

risk factors for newly developed vertebral fractures $(19,46-50)$.

Some experimental biomechanical studies showed that PVP or BKP increased stiffness and strength (5159). Additionally, the vertebrae treated with cement produced increased loading in adjacent vertebrae, inducing subsequent fractures $(25,55,56,60-63)$. Strangely, Berlemann et al (64) found the failure strength of functional spine units treated by augmentation with cement in one vertebral body was lower than that of untreated controls. In addition, a three-dimensional, non-linear finite element model by Rohlmann et al (65) showed that augmentation of vertebral bodies with bone cement had a much smaller effect on intradiscal pressure and endplate stress in the non-fractured vertebrae. They suggested that vertebral body fractures in adjacent vertebrae after PVP or PKP are not induced by increased stiffness of the treated vertebra, but instead that the anterior shift of the upper body was the dominating factor. Still another biomechanical study 
revealed that BKP may possibly decrease the incidence of adjacent level fracture (66). Interestingly, results suggest that post-fracture augmentation of vertebrae can increase failure load while stiffness was not restored, and stiffness appears to be maintained in prophylactic vertebroplasty but not in post-fracture vertebroplasty

Table 3. Methodological quality of each included study. Dropout rate $<20 \%$ indicates low risk of bias, $>20 \%$ indicates high risk of bias, if not reported, indicates unclear bias. Other bias indicates an important consideration in other domains that cannot solve bias.

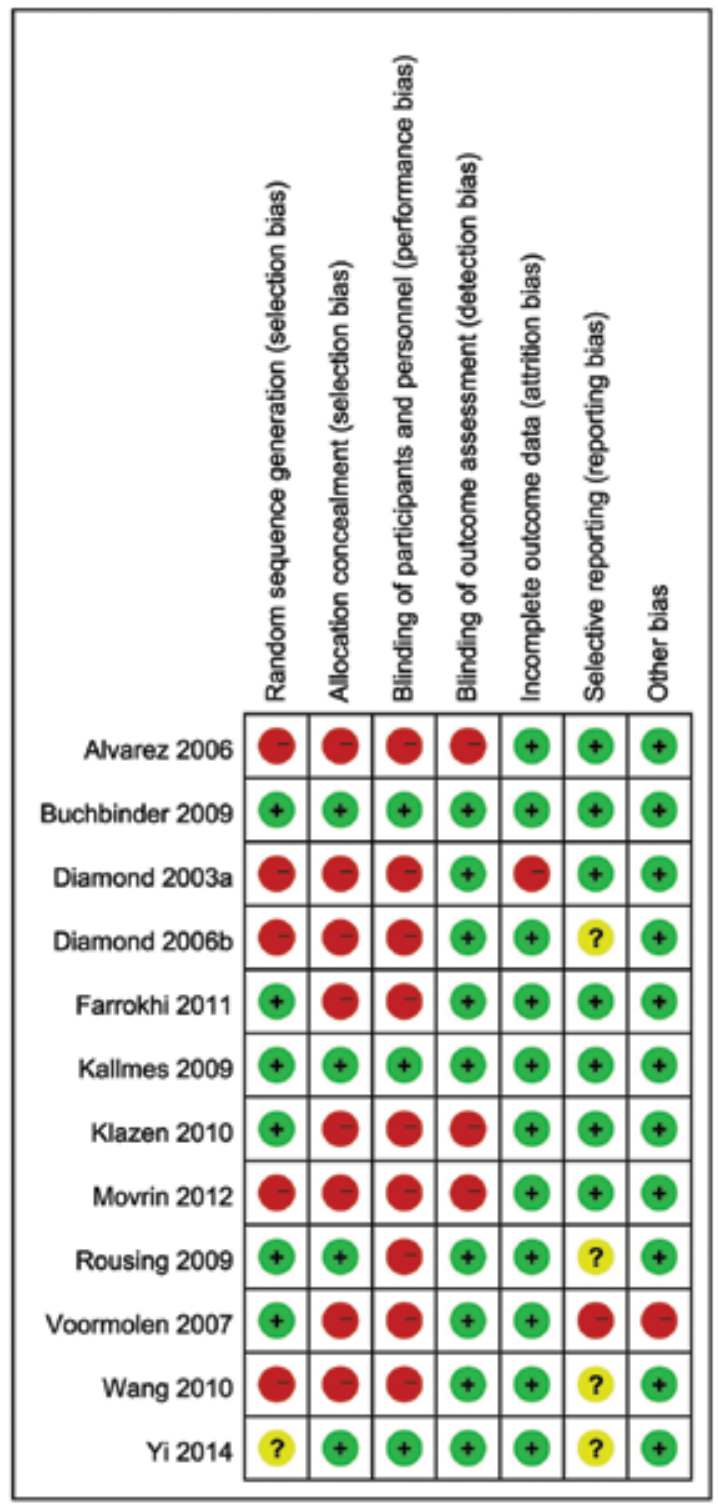

(67). Berlemann et al (64) postulated that the augmented vertebrae alter the biomechanics of load transfer to the adjacent vertebrae due to the increased stiffness, which they concluded based on the results of an experimental biomechanical study. Kim et al (68) showed that the greater the degree of height restoration after PVP, the greater the risk of new fracture. It seems that the resultant wedge deformation of the fractured vertebrae decreased, but the risk of new fracture increased. Though the cause is unknown, mechanical factors may be involved. A dynamic mechanical model of prophylactic augmentation found no significant difference in the stiffness of three-vertebral segment units pre- or post-augmentation in a laboratory investigation of human cadaveric three-vertebral functional spinal units (T12-L2) by Oakland et al (69). Another ex vivo biomechanical study indicated that kyphoplasty could restore the height of compressed vertebral bodies much more than could vertebroplasty during cyclic loading, while the latter had greater compression stiffness and less height reduction (52). It is possible that there is typically not extensive interdigitation of cement into the bone that surrounds the cavity that was created by the balloon. The load is then transferred to the underlying cancellous bone and then to the inferior endplate. The cancellous bone, which seemed to be damaged progressively under repetitive loading conditions, is likely the weakest link in this chain of force transmission. In vertebroplasty, the cement is injected in an interdigitated fashion throughout the fractured vertebral body, from endplate to endplate. Thus, the weaker cancellous bone is not loaded progressively as it is with the kyphoplasty technique. Another biomechanical study by Villarraga et al (70) showed that the stress and strain of spinal levels adjacent to those treated with BKP were minimal and were within the damage tolerance limits of cancellous and cortical bones. Thus, despite the clinical evidence supporting an increased risk of new fractures in vertebrae adjacent to treated levels and the biomechanical studies suggesting a plausible mechanism for these fractures, there is still no proof that vertebroplasty causes adjacent fractures $(25,63)$.

The biomaterials, such as PMMA cement, used in these operations may play an important role in load transfer and disc mechanics; therefore, difference in cement volume, formulation, and distribution should also be evaluated $(71,72)$. Kim et al $(73)$ developed a threedimensional finite-element model of a functional spinal unit to determine the optimal stiffness and volume of bone cement and their biomechanical effects on the ad- 
Does Vertebroplasty for Osteoporotic Vertebral Fracture Increase New-level Vertebral Fracture?

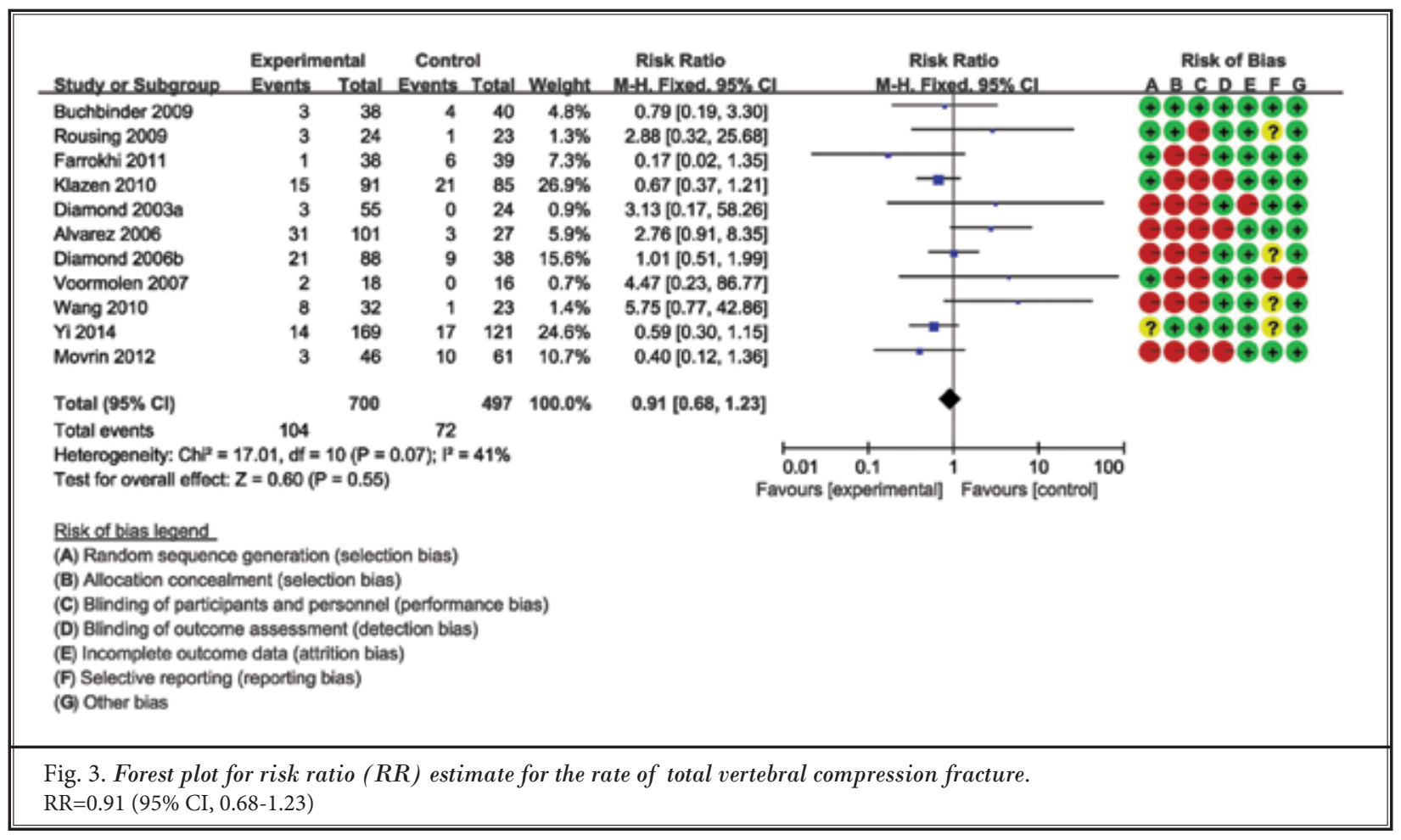

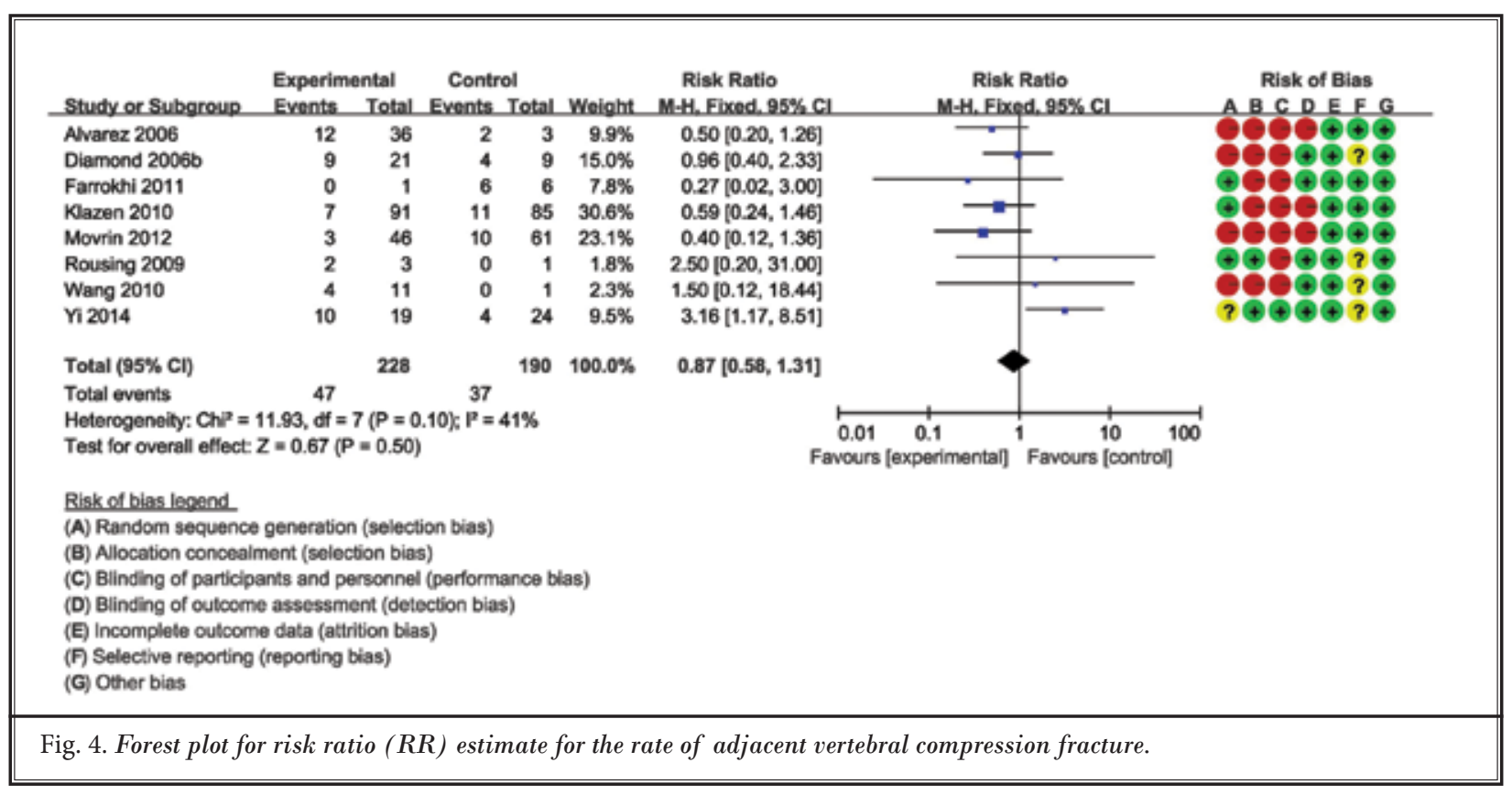

jacent vertebrae. They demonstrated that bone cement volume can have a significant effect on the occurrence of subsequent vertebral fractures after vertebroplasty and that stiffness increases further with bone cement volume higher than $30 \%$, resulting in the subsequent fracture of adjacent vertebral bodies, most likely in the cranial direction. The cement transfers a greater proportion of the load through the central augmented trabecular structure than that occurring naturally, causing an altered load distribution within the spinal seg- 


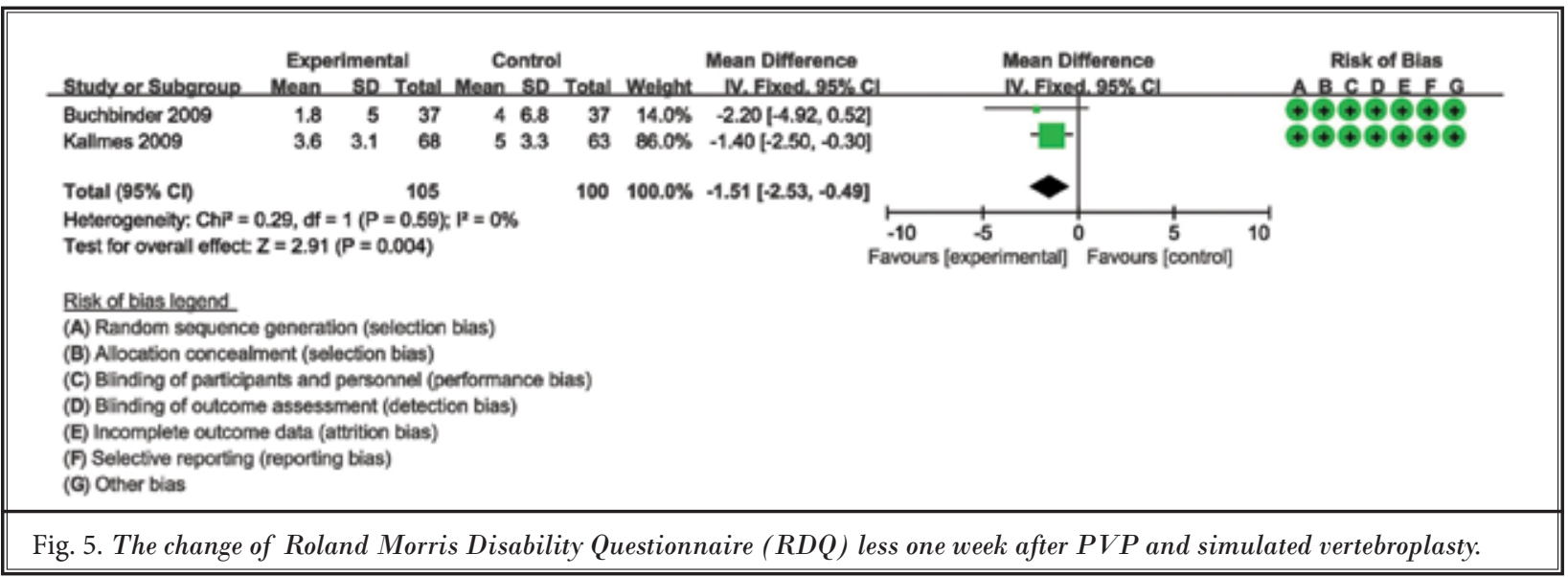

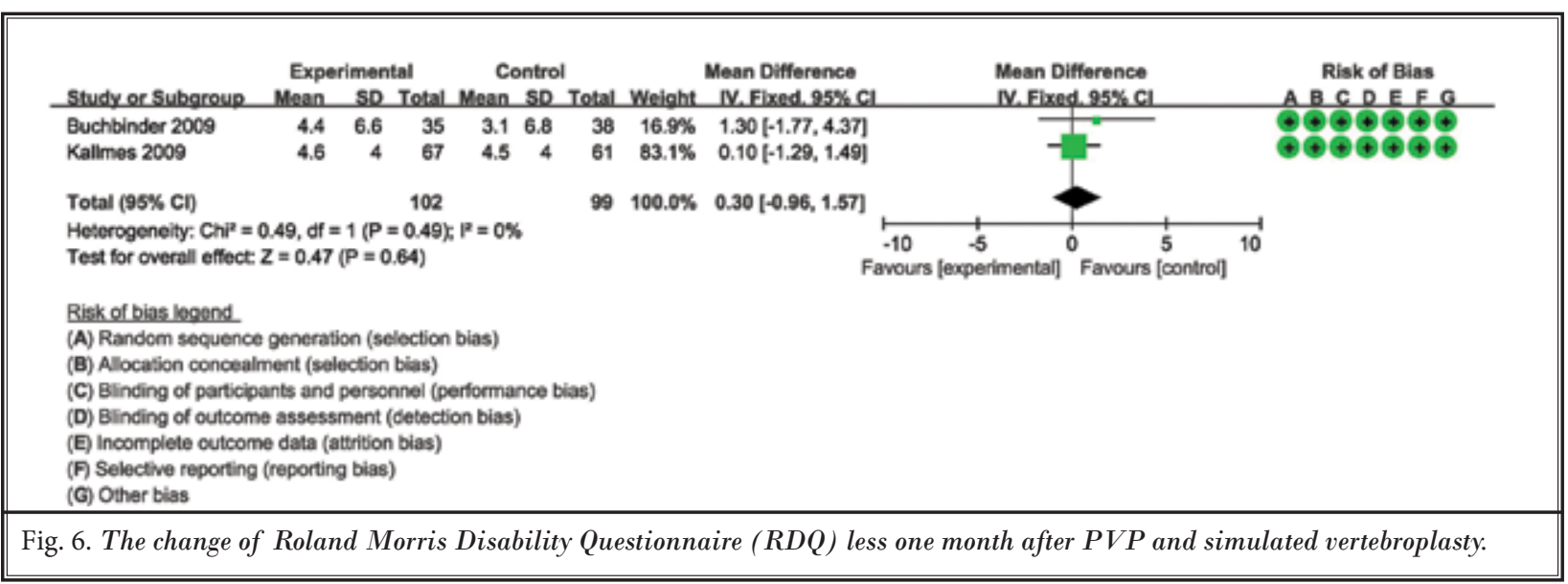

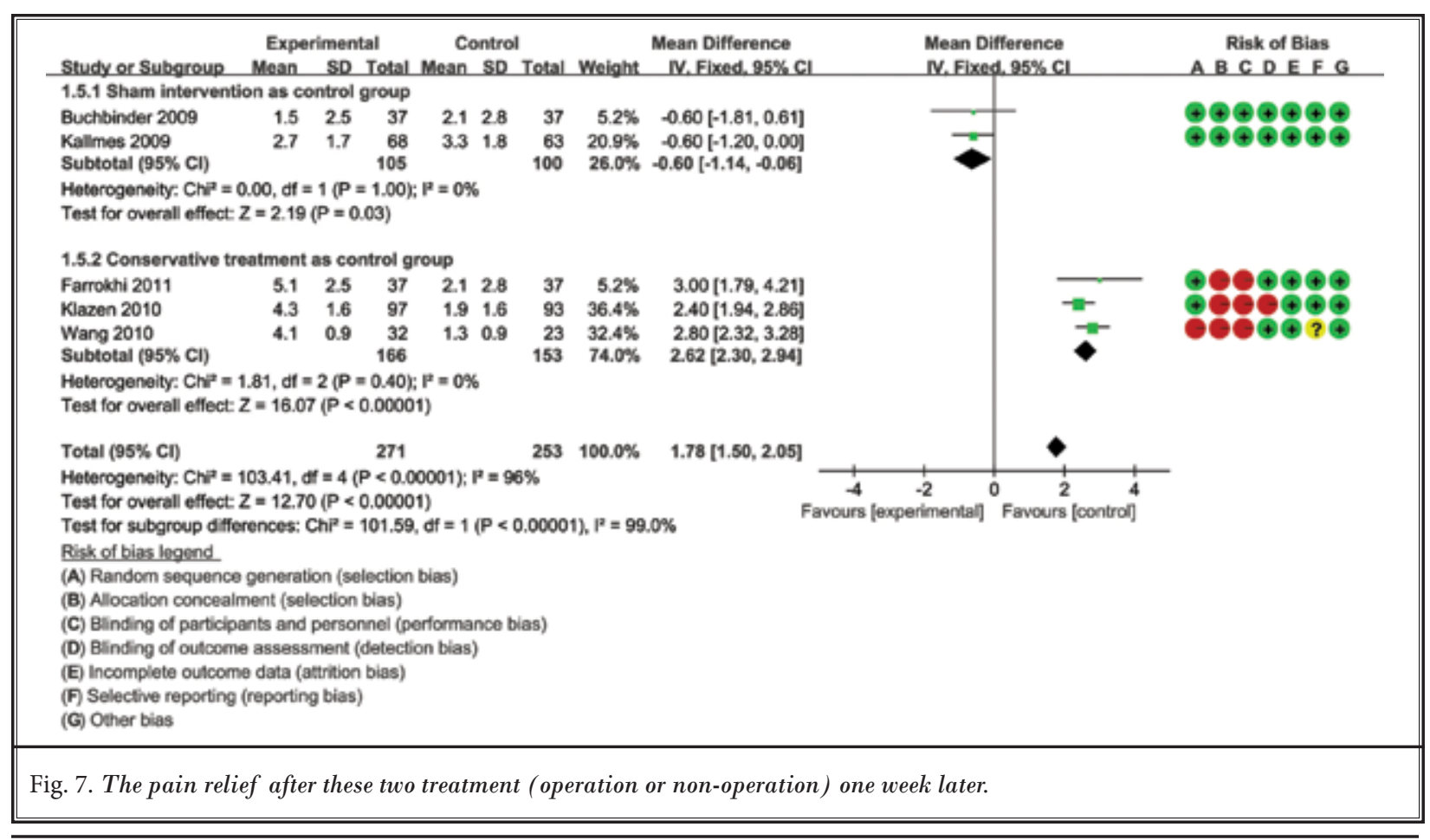


Does Vertebroplasty for Osteoporotic Vertebral Fracture Increase New-level Vertebral Fracture?

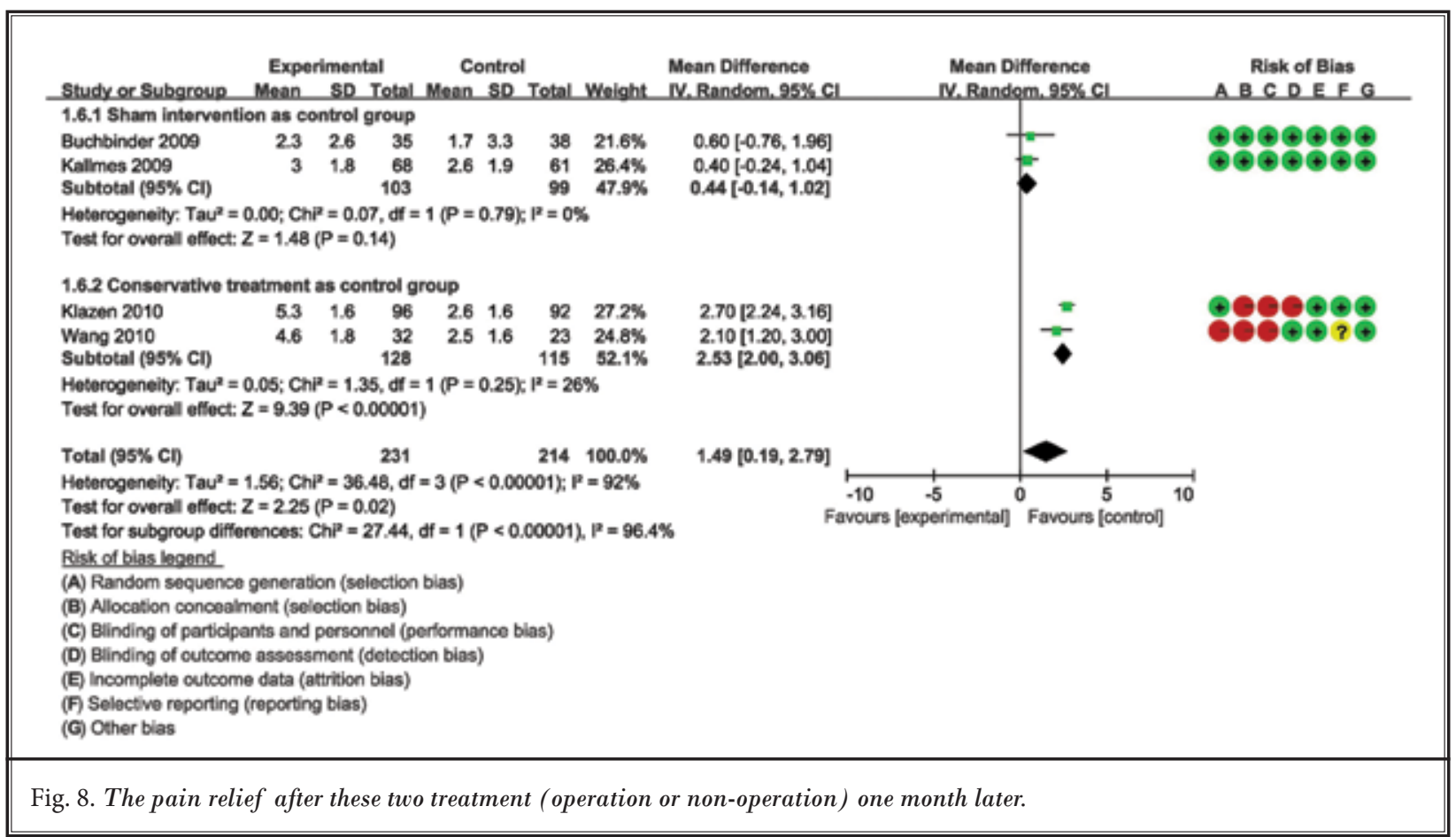

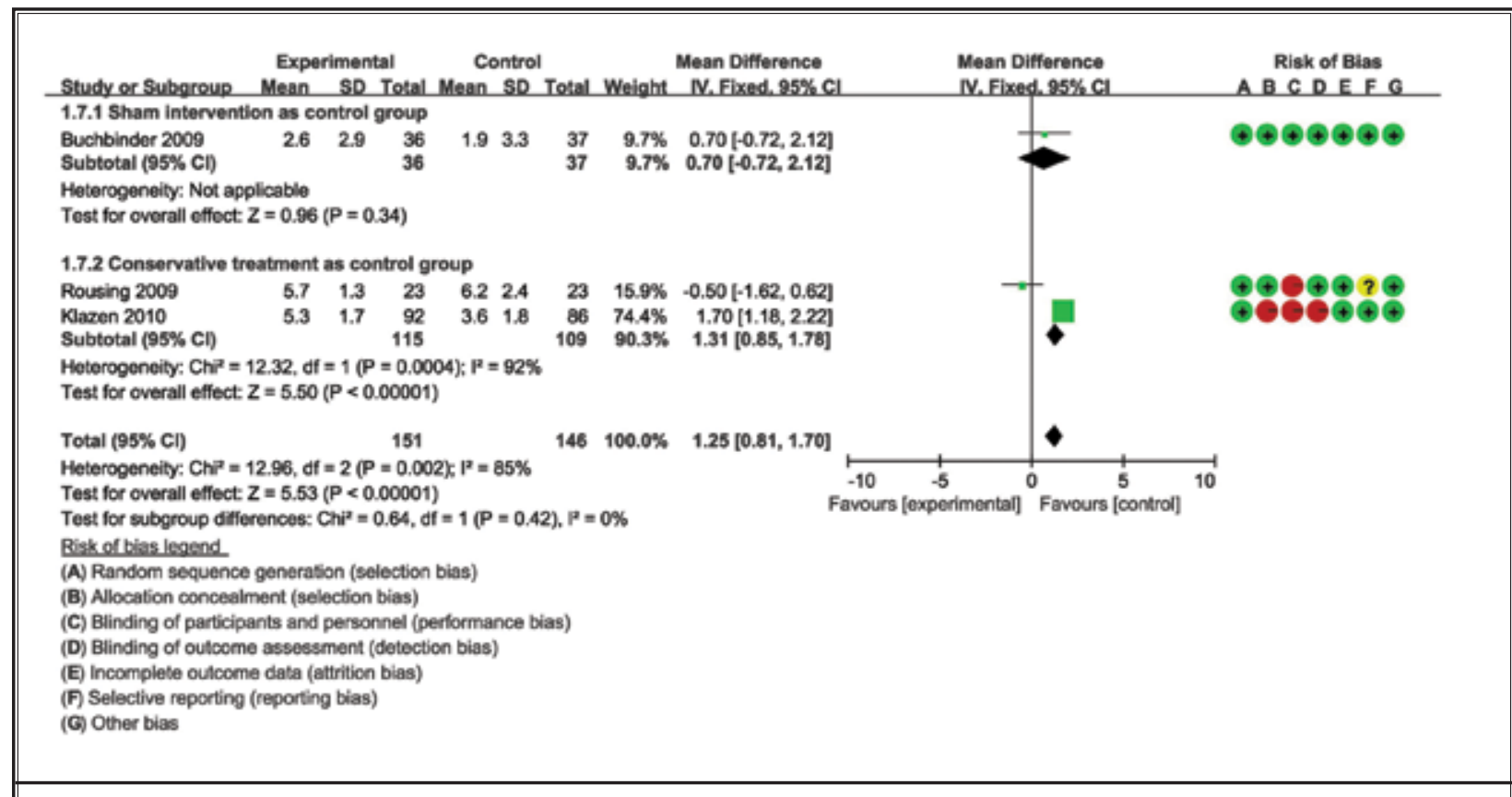

Fig. 9. The pain relief after these two treatment (operation or non-operation) 3 month later.

ment. Some authors reported that cement leakage into the disc can increase the risk of adjacent new vertebral fracture after PVP, and augmentation to the fracture body increased mechanical pressure, which is especially pertinent for patients who increase their daily activities as their back pain decreases after the procedure, as it places additional stress on the vertebral bodies $(74,75)$. Thus, many surgeons believe that the stiffening of the 


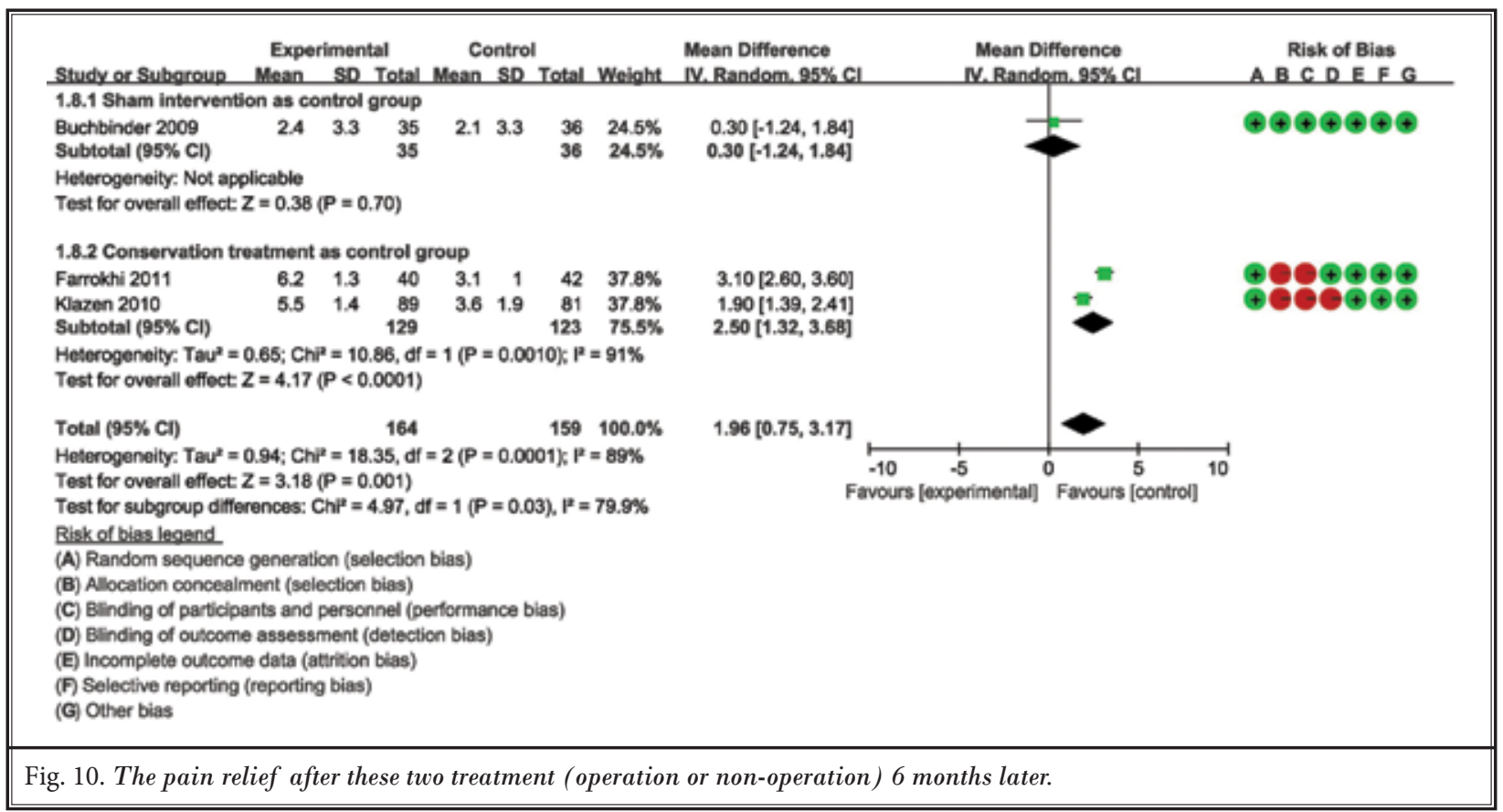

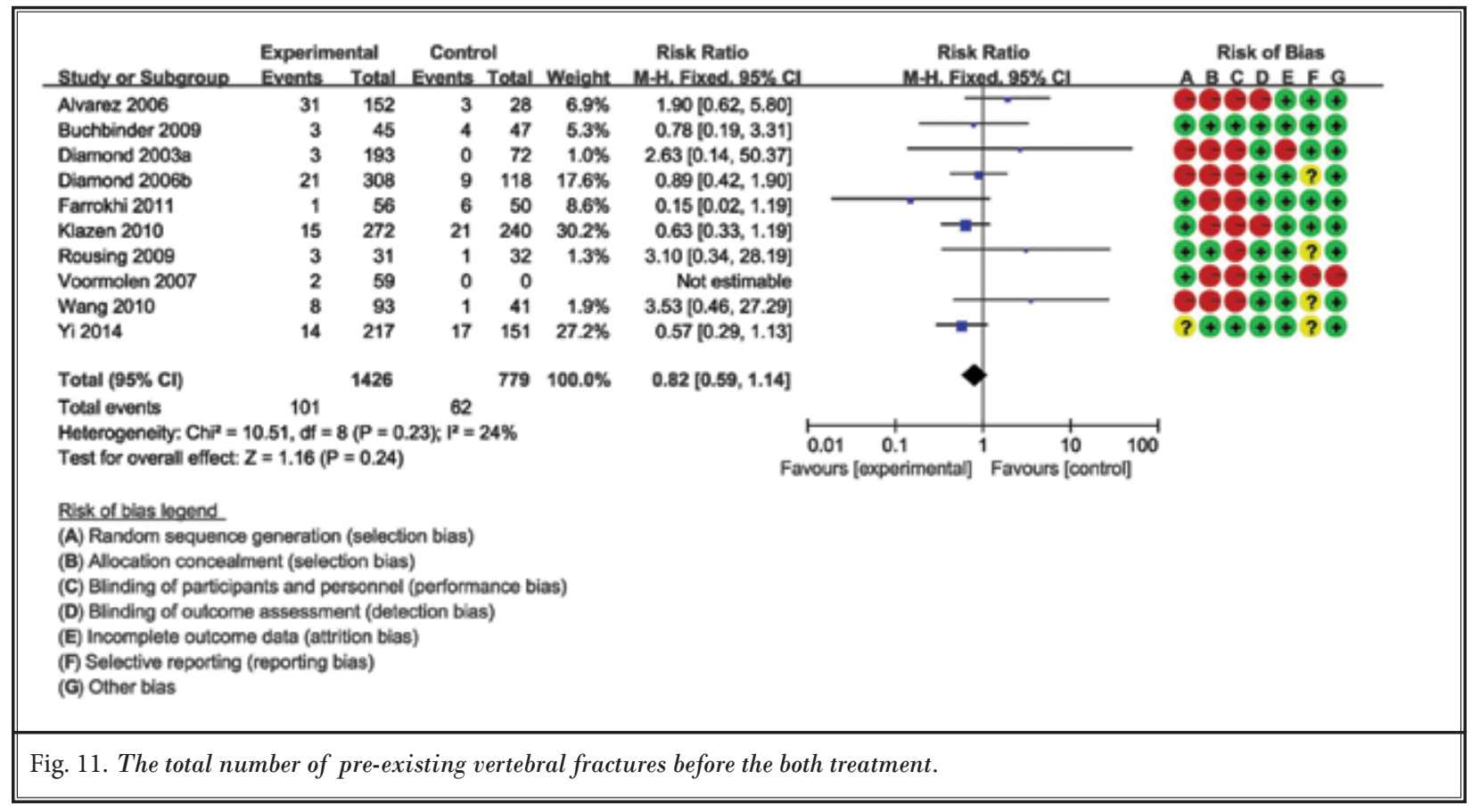

augmented vertebral body may be a risk factor for subsequent fracture.

However, few randomized clinical studies have reported on this topic. In our meta-analysis, we selected 12 studies, including 5 randomized controlled trials, to evaluate whether new vertebral fracture after PVP is associated with this minimally invasive surgery, or if it is simply the natural progression of the osteoporosis. The results indicate that there was no significant difference in the re-fracture ratio after vertebroplasty or kyphoplasty when compared to non-operative treatment. There were no statistical differences in the fol- 


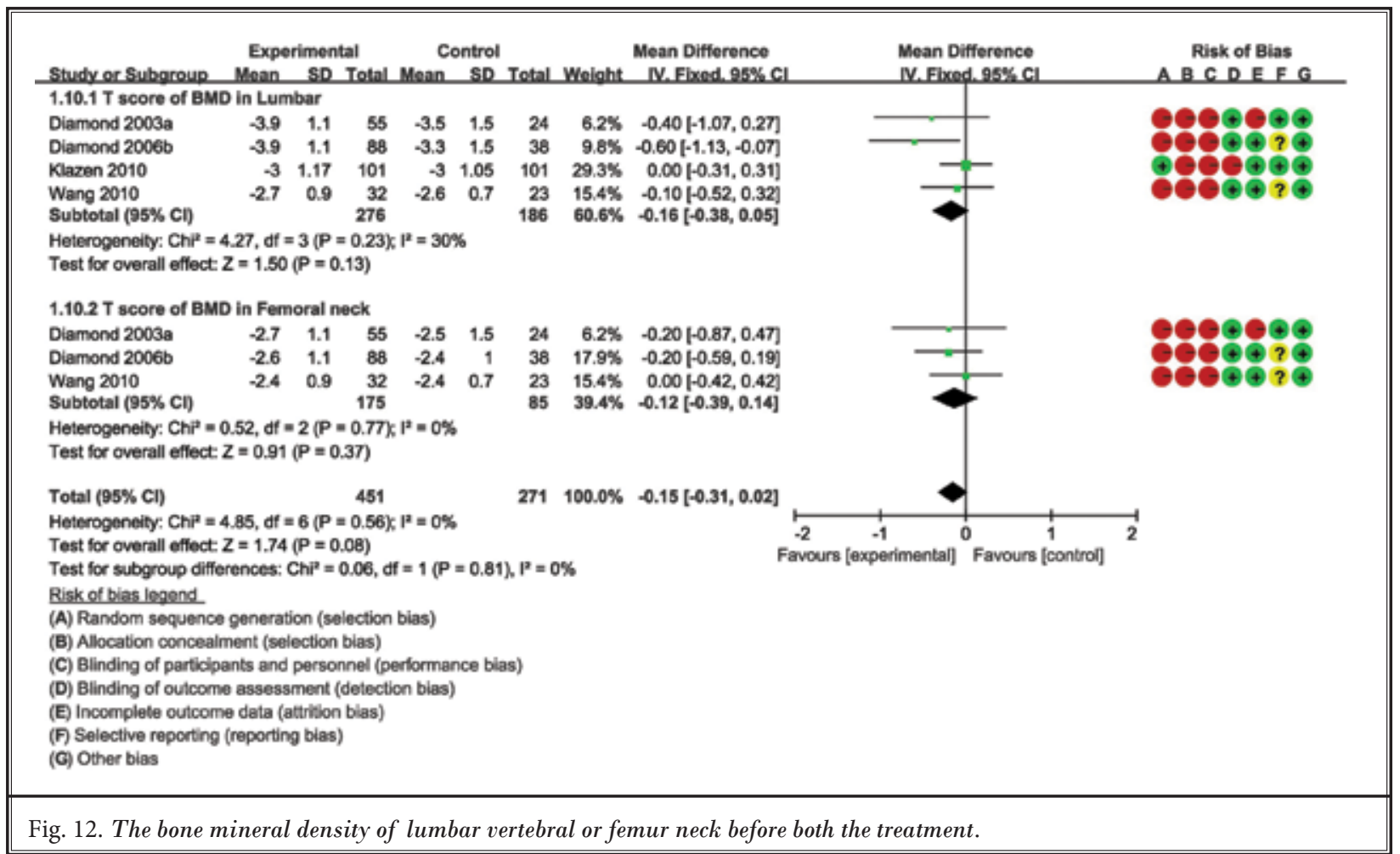

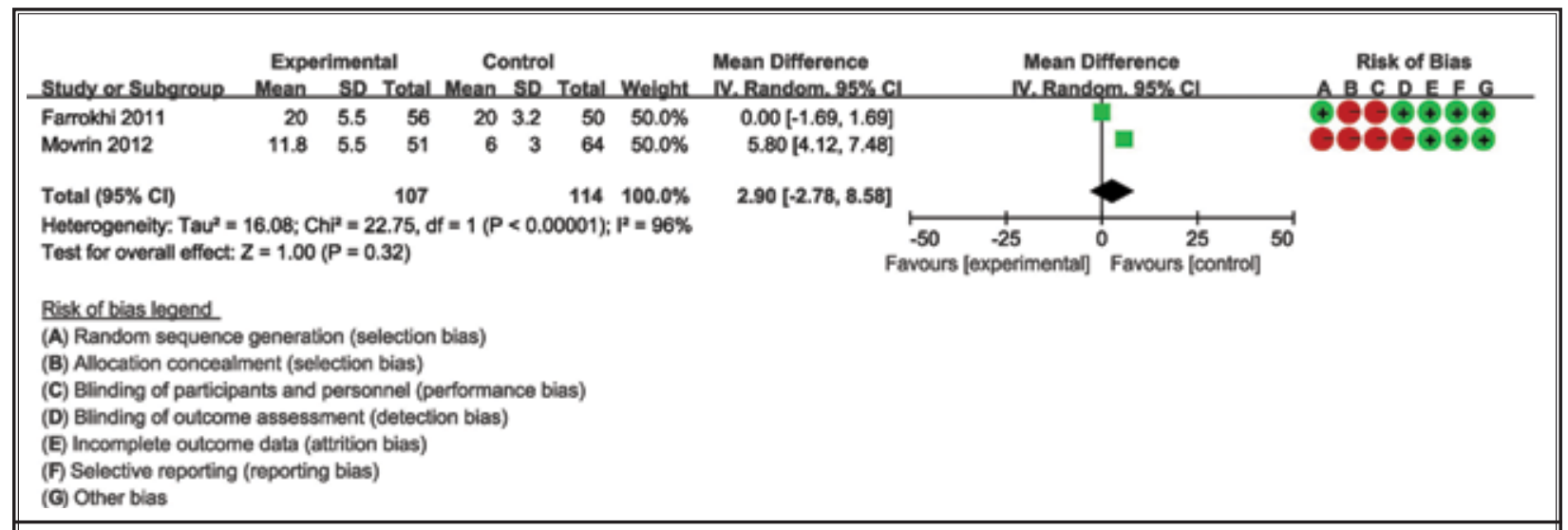

Fig. 13. The local kyphotic angel of pre-treatment fracture vertebraes.

lowing factors: the number of pre-existing vertebral fractures, the BMD of the lumbar or femoral necks, the age, the proportion of women, the local kyphotic angle of the pre-treated fracture bodies, and the severity of the fracture body. However, as many authors have reported, both procedures had a more favorable effect on pain relief compared with conservative treatment in these randomized clinical trials $(27,39,41)$. Therefore, we believe that the presence of new vertebral fracture is not due to the augmentation but rather that subse- quent level fractures may be related to the bone itself (that is, to osteoporosis rather than to the surgical intervention). This viewpoint is similar to that described in a randomized controlled trial in 2009 by Rousing et al (39).

\section{Limitations}

One limitation in this review is that it included one randomized controlled trial that did not report new vertebral fractures; thus, it may have added data 


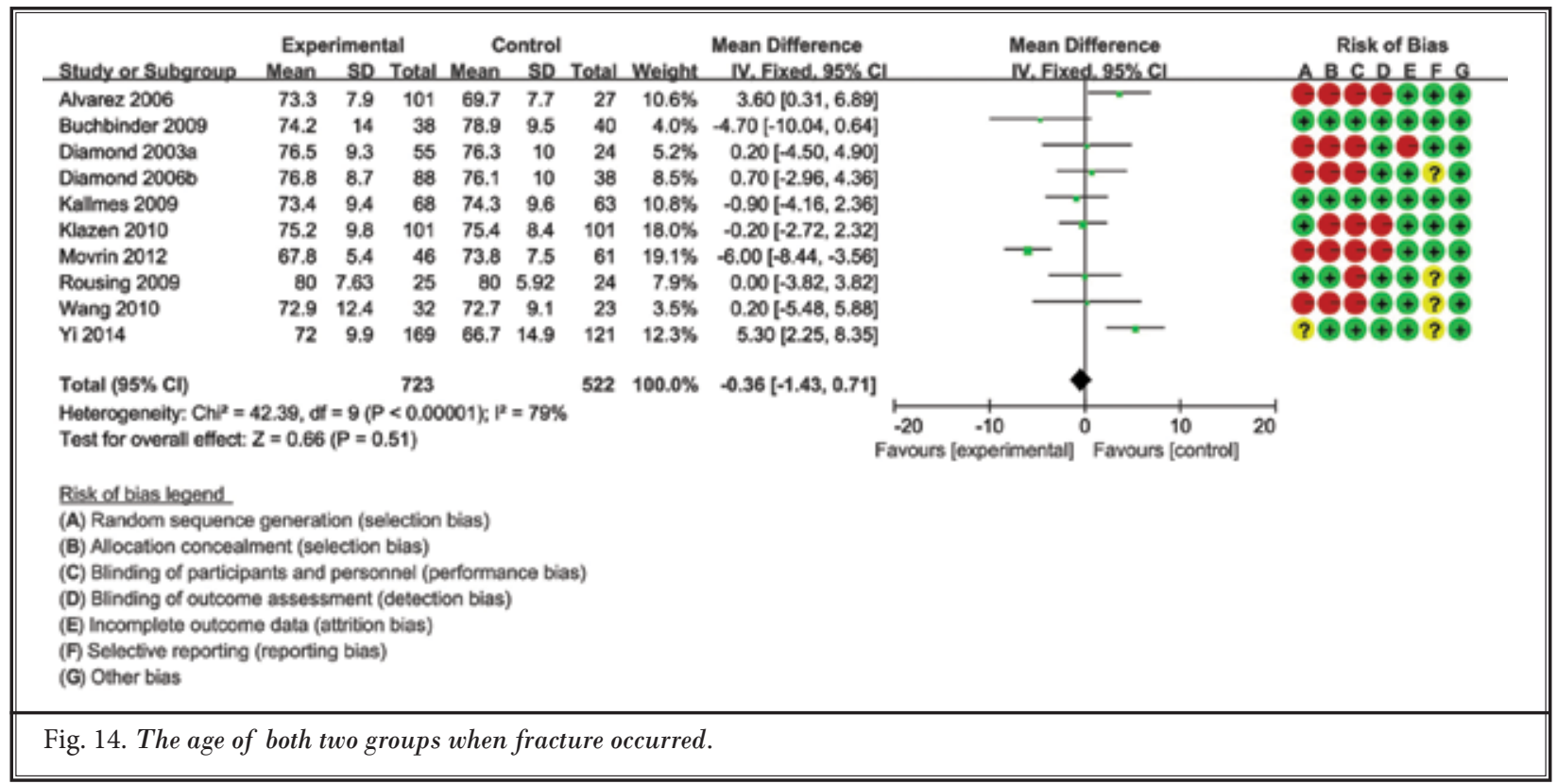

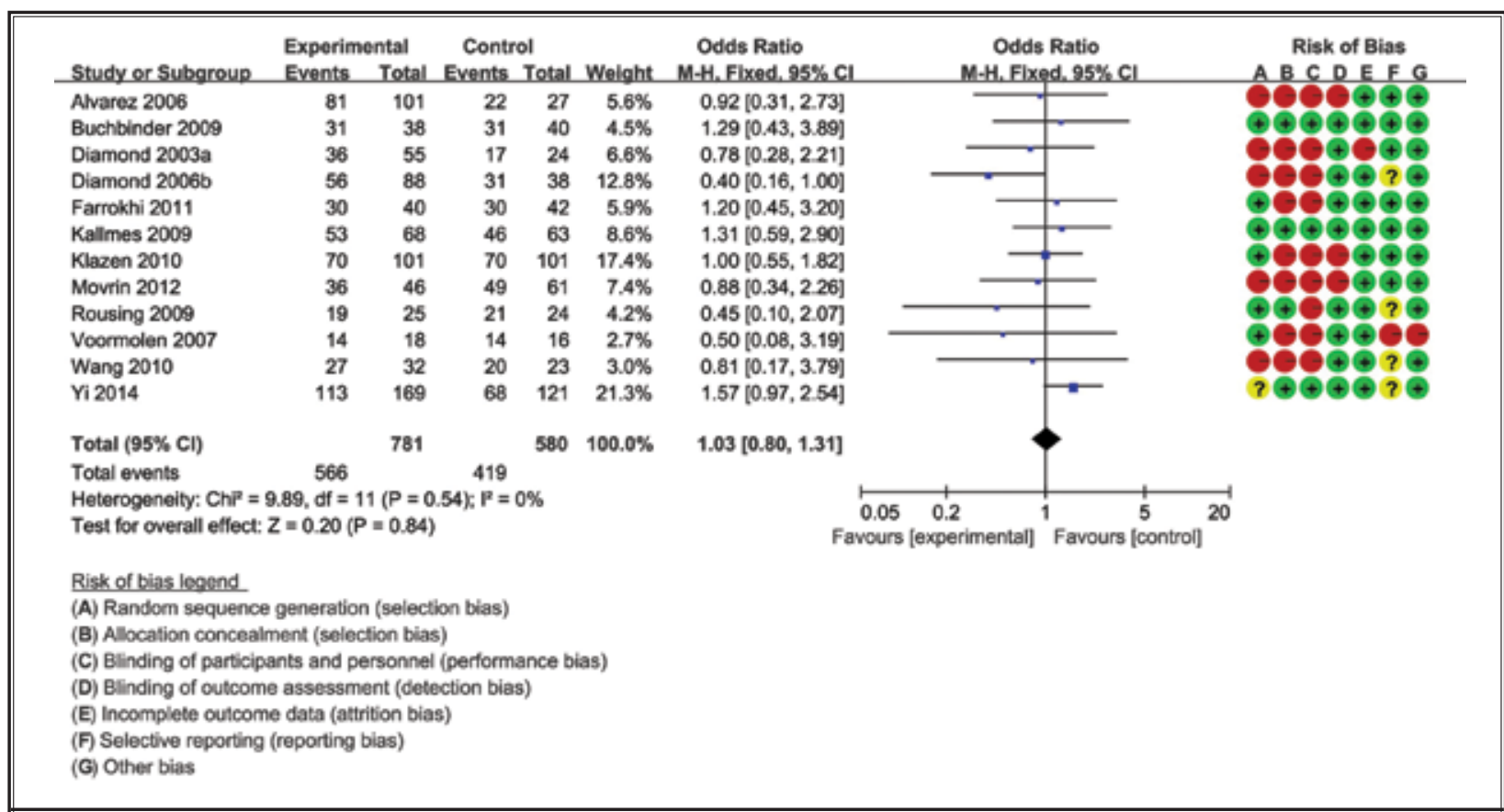

Fig. 15. The female ratio of both two groups when fracture occurred.

that should not have been included in the final results (40). Our study may also be limited by reporting bias. Another limitation is the inclusion of studies after we searched the online databases. We did not include unpublished studies, which might have led to a publication bias in our review. However, the risk of publication bias exists in any meta-analyses, and we believe that our review is convincing in its final results. Therefore, our results should be interpreted and applied prudently. Unfortunately, many studies did not record or state the specific time when the new fracture occurred. Thus, it is possible that some fractures could not be found ear- 
Does Vertebroplasty for Osteoporotic Vertebral Fracture Increase New-level Vertebral Fracture?

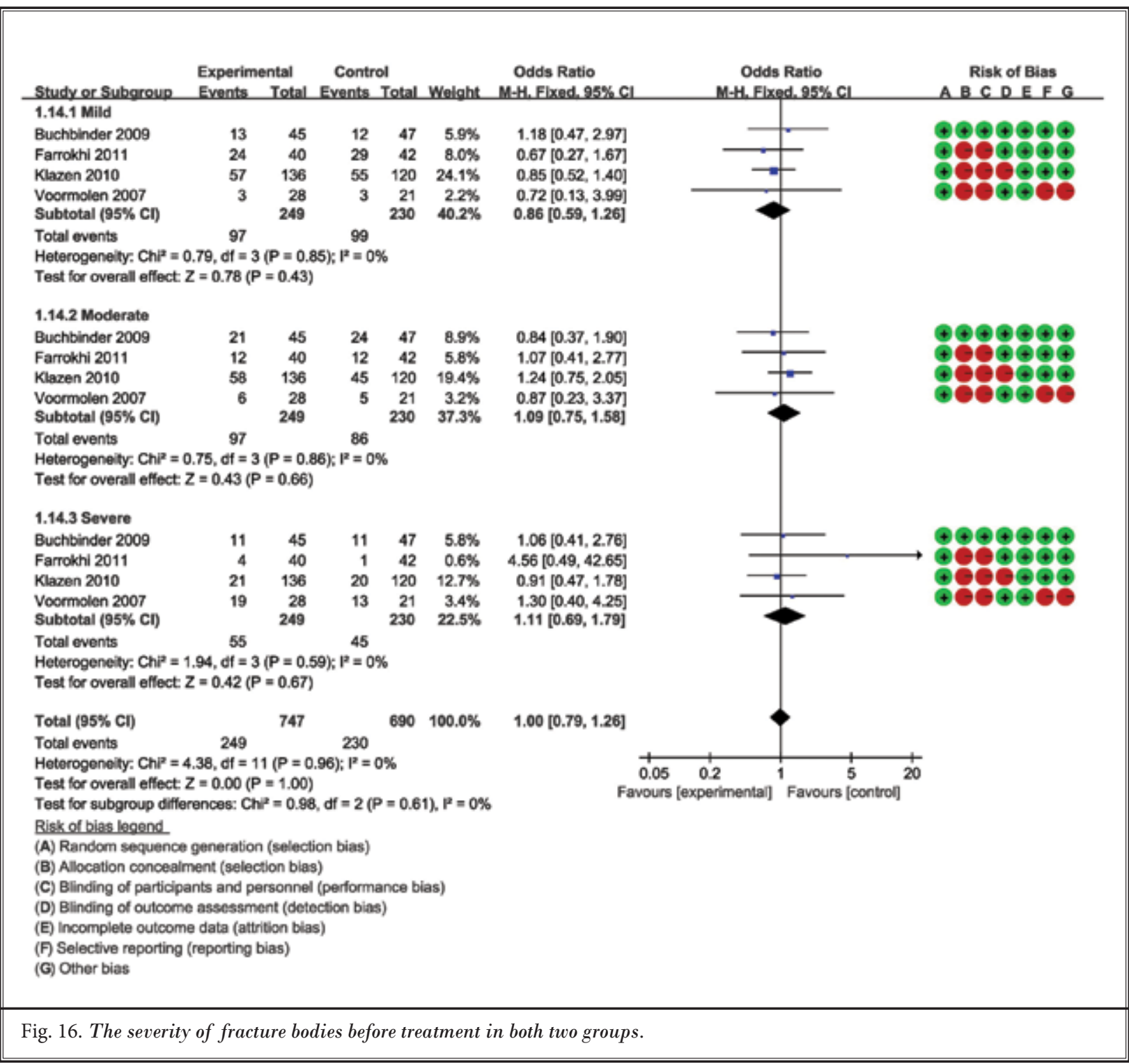

lier because of the possibility that some new fractures occurred without back pain. Thus, future high quality studies are still needed, such as randomized controlled trials, to determine whether new vertebral fractures occur after PVP or BKP.

\section{Conclusion}

Based on this meta-analysis, we conclude that PVP and BKP as minimally invasive surgeries for treating
OVCF are better choices than conventional treatment, as these techniques not only immediately alleviate back pain but also avoid many complications of patients being bedridden with conservative treatment. Moreover, these procedures may not result in a greater incidence of new vertebral fractures in terms of the total number or the number of breaks adjacent to the treated one compared with conservative therapy. 


\section{References}

1. Suzuki N, Ogikubo O, Hansson T. The course of the acute vertebral body fragility fracture: Its effect on pain, disability and quality of life during 12 months. Eur Spine ] 2008; 17:1380-1390.

2. Riek AE, Towler DA. The pharmacological management of osteoporosis. Mo Med 2011; 108:118-123.

3. Evans AJ, Jensen ME, Kip KE, DeNardo AJ, Lawler GJ, Negin GA, Remley KB, Boutin SM, Dunnagan SA. Vertebral compression fractures: Pain reduction and improvement in functional mobility after percutaneous polymethylmethacrylate vertebroplasty retrospective report of 245 cases. Radiology 2003; 226:366-372.

4. Hulme PA, Krebs J, Ferguson SJ, Berlemann U. Vertebroplasty and kyphoplasty: A systematic review of 69 clinical studies. Spine (Phila Pa 1976) 2006; 31:1983-2001.

5. Voormolen $\mathrm{MH}$, Lohle PN, Lampmann LE, van den Wildenberg W, Juttmann $\mathrm{JR}$, Diekerhof $\mathrm{CH}$, de Waal MJ. Prospective clinical follow-up after percutaneous vertebroplasty in patients with painful osteoporotic vertebral compression fractures. J Vasc Interv Radiol 2006; 17:1313-1320.

6. Anselmetti GC, Corrao G, Monica PD, Tartaglia V, Manca A, Eminefendic H, Russo F, Tosetti I, Regge D. Pain relief following percutaneous vertebroplasty: Results of a series of 283 consecutive patients treated in a single institution. Cardiovasc Intervent Radiol 2007; 30:441-447.

7. Klazen CA, Lohle PN, de Vries J, Jansen $\mathrm{FH}$, Tielbeek AV, Blonk MC, Venmans A, van Rooij WJ, Schoemaker MC, Juttmann JR, Lo TH, Verhaar HJ, van der Graaf $\mathrm{Y}$, van Everdingen KJ, Muller AF, Elgersma OE, Halkema DR, Fransen $\mathrm{H}$, Janssens X, Buskens E, Mali WP. Vertebroplasty versus conservative treatment in acute osteoporotic vertebral compression fractures (Vertos II): An openlabel randomised trial. Lancet 2010; 376:1085-1092.

8. Rousing R, Hansen KL, Andersen MO, Jespersen SM, Thomsen K, Lauritsen JM. Twelve-months follow-up in fortynine patients with acute/semiacute osteoporotic vertebral fractures treated conservatively or with percutaneous vertebroplasty: A clinical randomized study. Spine (Phila Pa 1976) 2010; 35:478-82.

9. Garfin SR, Yuan HA, Reiley MA. New technologies in spine: kyphoplasty and vertebroplasty for the treatment of painful osteoporotic compression fractures. Spine (Phila Pa 1976) 2001; 26:1511-1515.

10. Lieberman IH, Dudeney S, Reinhardt MK, Bell G. Initial outcome and efficacy of "kyphoplasty" in the treatment of painful osteoporotic vertebral compression fractures. Spine (Phila Pa 1976) 2001; 26:1631-1638.

11. Lieberman I, Reinhardt MK. Vertebroplasty and kyphoplasty for osteolytic vertebral collapse. Clin Orthop Relat Res 2003; 415:S176-S186.

12. Voggenreiter G. Balloon kyphoplasty is effective in deformity correction of osteoporotic vertebral compression fractures. Spine (Phila Pa 1976) 2005; 30:2806-2812.

13. Bouza C, Lopez T, Magro A, Navalpotro L, Amate JM. Efficacy and safety of balloon kyphoplasty in the treatment of vertebral compression fractures: a systematic review. Eur Spine J 2006; 15:1050-1067.

14. Garfin SR, Buckley RA, Ledlie J. Balloon kyphoplasty for symptomatic vertebral body compression fractures results in rapid, significant, and sustained improvements in back pain, function, and quality of life for elderly patients. Spine (Phila Pa 1976) 2006; 31:2213-2220.

15. Taylor RS, Fritzell P, Taylor RJ. Balloon kyphoplasty in the management of vertebral compression fractures: An updated systematic review and meta-analysis. Eur Spine ] 2007; 16:1085-1100.

16. Zhang GL, Ge BF. [Percutaneous vertebroplasty complications]. Zhongguo Gu Shang 2013; 26:257-260.

17. Lin H, Bao LH, Zhu XF, Qian C, Chen X, Han ZB. Analysis of recurrent fracture of a new vertebral body after percutaneous vertebroplasty in patients with osteoporosis. Orthop Surg 2010; 2:119-123.

18. Lo YP, Chen WJ, Chen LH, Lai PL. New vertebral fracture after vertebroplasty. J Trauma 2008; 65:1439-1445.

19. Al-Nakshabandi NA. Percutaneous vertebroplasty complications. Ann Saud Med 2011; 31:294-297.

20. Omidi-Kashani F, Hasankhani EG, Ebrahimzadeh MH, Kachooei AR, Hasani M, Moradi A. Percutaneous vertebroplasty in Iranian patients with osteoporotic vertebral fractures. Arch Bone Jt Surg 2013; 9-13.

21. Toru U, Coskun T, Acat M, Onaran H, Gul S, Cetinkaya E. Pulmonary cement embolism following percutaneous ver- tebroplasty. Case Rep Pulmonol 2014; 2014:851573.

22. Rothermich MA, Buchowski JM, Bumpass DB, Patterson GA. Pulmonary cement embolization after vertebroplasty requiring pulmonary wedge resection. Clin Orthop Relat Res 2014; 472:1652-1657.

23. Civelek E, Cansever T, Yilmaz C, Kabatas S, Gulsen S, Aydemir F, Altiotanors $\mathrm{N}$, Caner $\mathrm{H}$. The retrospective analysis of the effect of balloon kyphoplasty to the adjacent-segment fracture in 171 patients. J Spinal Discord Tech 2014; 27:98-104.

24. Lindsay R, Silverman SL, Cooper C, Hanley DA, Barton I, Broy SB, Licata A, Benhamou L, Geusens P, Flowers K, Stracke $H$, Seeman E. Risk of new vertebral fracture in the year following a fracture. JAMA 2001; 285:320-323.

25. Uppin AA, Hirsch JA, Centenera LV, Pfiefer BA, Pazianos AG, Choi IS. Occurrence of new vertebral body fracture after percutaneous vertebroplasty in patients with osteoporosis. Radiology 2003; 226:119-124.

26. Pflugmacher R, Schroeder RJ, Klostermann CK. Incidence of adjacent vertebral fractures in patients treated with balloon kyphoplasty: Two years' prospective follow-up. Acta Radiol 2006; 47:830-840.

27. Farrokhi MR, Alibai E, Maghami Z. Randomized controlled trial of percutaneous vertebroplasty versus optimal medical management for the relief of pain and disability in acute osteoporotic vertebral compression fractures. ] Neurosurg Spine 2011; 14:561-569.

28. Diamond TH, Bryant C, Browne L, Clark WA. Clinical outcomes after acute osteoporotic vertebral fractures: A 2-year non-randomised trial comparing percutaneous vertebroplasty with conservative therapy. Med J Aust 2006; 184:113-117.

29. Trout AT, Kallmes DF. Does vertebroplasty cause incident vertebral fractures? A review of available data. AJNR Am J Neuroradiol 2006; 27:1397-1403.

30. Wang HK, Lu K, Liang CL, Weng $\mathrm{HC}$, Wang KW, Tsai YD, Hsieh CH, Liliang PC. Comparing clinical outcomes following percutaneous vertebroplasty with conservative therapy for acute osteoporotic vertebral compression fractures. Pain Med 2010; 11:1659-1665.

31. Yi X, Lu H, Tian F, Wang Y, Li C, Liu H, Liu X, Li H. Recompression in new levels after percutaneous vertebroplasty and 
kyphoplasty compared with conservative treatment. Arch Orthop Trauma Surg 2014; 134:21-30.

32. Movrin I. Adjacent level fracture after osteoporotic vertebral compression fracture: A nonrandomized prospective study comparing balloon kyphoplasty with conservative therapy. Wien Klin Wochenschr 2012; 124:304-311.

33. He SC, Teng GJ, Deng G, Fang W, Guo $J$ H, Zhu GY, Li GZ. Repeat vertebroplasty for unrelieved pain at previously treated vertebral levels with osteoporotic vertebral compression fractures. Spine (Phila Pa 1976) 2008; 33:640-647.

34. Uebelhart B, Casez P, Rizzoli R, LouisSimonet M. Prophylactic injection of methylmetacrylate in vertebrae located between two previously cemented levels does not prevent a subsequent compression fracture in a patient with bone fragility. Joint Bone Spine 2008; 75:322-324.

35. Diamond TH, Champion B, Clark WA. Management of acute osteoporotic vertebral fractures: A nonrandomized trial comparing percutaneous vertebroplasty with conservative therapy. Am J Med 2003; 114:257-265.

36. Alvarez L, Alcaraz M, Perez-Higueras A, Granizo J, de Miguel I, Rossi RE, Quinones D. Percutaneous vertebroplasty: Functional improvement in patients with osteoporotic compression fractures. Spine (Phila Pa 1976) 2006; 31:1113-1118.

37. Voormolen $\mathrm{MH}$, Mali WP, Lohle PN, Fransen $H$, Lampmann LE, van der Graaf Y, Juttmann JR, Jansssens X, Verhaar $H J$. Percutaneous vertebroplasty compared with optimal pain medication treatment: Short-term clinical outcome of patients with subacute or chronic painful osteoporotic vertebral compression fractures. The VERTOS study. AJNR 2007; 28:555-560.

38. Buchbinder R, Osborne RH, Ebeling PR, Wark JD, Mitchell P, Wriedt C, Graves S, Staples MP, Murphy B. A randomized trial of vertebroplasty for painful osteoporotic vertebral fractures. N Engl J Med 2009; 361:557-568.

39. Rousing R, Andersen MO, Jespersen SM, Thomsen K, Lauritsen J. Percutaneous vertebroplasty compared to conservative treatment in patients with painful acute or subacute osteoporotic vertebral fractures: Three-months follow-up in a clinical randomized study. Spine (Phila Pa 1976) 2009; 34:1349-1354.

40. Kallmes DF, Comstock BA, Heagerty
PJ, Turner JA, Wilson DJ, Diamond TH, Edwards R, Gray LA, Stout L, Owen S, Hollingworth W, Ghdoke B, AnnesleyWilliams DJ, Ralston SH, Jarvik JG. A randomized trial of vertebroplasty for osteoporotic spinal fractures. $N$ Engl J Med 2009; 361:569-579.

41. Klazen CA, Lohle PN, de Vries J, Jansen $\mathrm{FH}$, Tielbeek AV, Blonk MC, Venmans A, van Rooij WJ, Schoemaker MC, Juttmann JR, Lo TH, Verhaar HJ, van der Graaf $\mathrm{Y}$, van Everdingen $\mathrm{KJ}$, Muller AF, Elgersma OE, Halkema DR, Fransen $\mathrm{H}$, Janssens X, Buskens E, Mali WP. Vertebroplasty versus conservative treatment in acute osteoporotic vertebral compression fractures (Vertos II): An openlabel randomised trial. Lancet 2010; 376:1085-1092.

42. Furlan AD, Pennick V, Bombardier C, van Tulder M. 2009 updated method guidelines for systematic reviews in the Cochrane Back Review Group. Spine (Phila Pa 1976) 2009; 34:1929-1941.

43. Galibert P, Deramond H, Rosat P, Le Gars D. [Preliminary note on the treatment of vertebral angioma by percutaneous acrylic vertebroplasty]. Neurochirurgie 1987; 33:166-168.

44. Chiras J, Depriester C, Weill A, SolaMartinez MT, Deramond H. [Percutaneous vertebral surgery. Technics and indications]. J Neuroradiol 1997; 24:45-59.

45. Cyteval C, Sarrabere MP, Roux JO, Thomas E, Jorgensen C, Blotman F, Sany J, Taourel P. Acute osteoporotic vertebral collapse: Open study on percutaneous injection of acrylic surgical cement in 20 patients. AJR Am J Roentgenol 1999; 173:1685-1690.

46. Bouza C, Lopez T, Magro A, Navalpotro L, Amate JM. Efficacy and safety of balloon kyphoplasty in the treatment of vertebral compression fractures: A systematic review. Eur Spine J 2006; 15:1050-1067.

47. Lee WS, Sung KH, Jeong HT, Sung YS, Hyun YI, Choi JY, Lee KS, Ok CS, Choi YW. Risk factors of developing new symptomatic vertebral compression fractures after percutaneous vertebroplasty in osteoporotic patients. Eur Spine J 2006; 15:1777-1783.

48. Ahn Y, Lee JH, Lee HY, Lee SH, Keem $\mathrm{SH}$. Predictive factors for subsequent vertebral fracture after percutaneous vertebroplasty. J Neurosurg Spine 2008; 9:129-136.

49. Lee KA, Hong SJ, Lee S, Cha IH, Kim BH, Kang EY. Analysis of adjacent fracture after percutaneous vertebroplasty: Does intradiscal cement leakage really increase the risk of adjacent vertebral fracture? Skeletal Radiol 2011; 40:1537-1542.

50. Rho YJ, Choe WJ, Chun YI. Risk factors predicting the new symptomatic vertebral compression fractures after percutaneous vertebroplasty or kyphoplasty. Eur Spine ] 2012; 21:905-911.

51. Seel EH, Davies EM. A biomechanical comparison of kyphoplasty using a balloon bone tamp versus an expandable polymer bone tamp in a deer spine model. J Bone Joint Surg Br 2007; 89:253-257.

52. Kim MJ, Lindsey DP, Hannibal M, Alamin TF. Vertebroplasty versus kyphoplasty: Biomechanical behavior under repetitive loading conditions. Spine (Phila $\mathrm{Pa}$ 1976) 2006; 31:2079-2084.

53. Wilcox RK. The biomechanical effect of vertebroplasty on the adjacent vertebral body: A finite element study. Proc Inst Mech Eng H 2006; 220:565-572.

54. Higgins KB, Harten RD, Langrana NA, Reiter MF. Biomechanical effects of unipedicular vertebroplasty on intact vertebrae. Spine (Phila Pa 1976) 2003; 28:1540-1547.

55. Polikeit A, Nolte LP, Ferguson SJ. The effect of cement augmentation on the load transfer in an osteoporotic functional spinal unit: finite-element analysis. Spine (Phila Pa 1976) 2003; 28:991-996.

56. Baroud G, Nemes J, Heini P, Steffen T. Load shift of the intervertebral disc after a vertebroplasty: A finite-element study. Eur Spine J 2003; 12:421-426.

57. Belkoff SM, Mathis JM, Fenton DC, Scribner RM, Reiley ME, Talmadge K. An ex vivo biomechanical evaluation of an inflatable bone tamp used in the treatment of compression fracture. Spine (Phila Pa 1976) 2001; 26:151-156.

58. Wilson DR, Myers ER, Mathis JM, Scribner RM, Conta JA, Reiley MA, Talmadge KD, Hayes WC. Effect of augmentation on the mechanics of vertebral wedge fractures. Spine (Phila Pa 1976) 2000; 25:158-165.

59. Tohmeh AG, Mathis JM, Fenton DC, Levine AM, Belkoff SM. Biomechanical efficacy of unipedicular versus bipedicular vertebroplasty for the management of osteoporotic compression fractures. Spine (Phila Pa 1976) 1999; 24:1772-1776.

6o. Fribourg D, Tang C, Sra P, Delamarter $\mathrm{R}$, Bae $\mathrm{H}$. Incidence of subsequent vertebral fracture after kyphoplasty. Spine (Phila Pa 1976) 2004; 29:2270-2276. 
61. Yuan HA, Brown CW, Phillips FM. Osteoporotic spinal deformity: A biomechanical rationale for the clinical consequences and treatment of vertebral body compression fractures. J Spinal Discord Tech 2004; 17:236-242.

62. Baroud G, Nemes J, Ferguson SJ, Steffen T. Material changes in osteoporotic human cancellous bone following infiltration with acrylic bone cement for a vertebral cement augmentation. Comput Methods Biomech Biomed Engin 2003; 6:133-139.

63. Grados F, Depriester C, Cayrolle G, Hardy N, Deramond H, Fardellone P. Longterm observations of vertebral osteoporotic fractures treated by percutaneous vertebroplasty. Rheumatology (Oxford) 2000; 39:1410-1414.

64. Berlemann U, Ferguson SJ, Nolte LP, Heini PF. Adjacent vertebral failure after vertebroplasty. A biomechanical investigation. J Bone Joint Surg $\mathrm{Br}$ 2002; 84:748-752.

65. Rohlmann A, Zander T, Bergmann G. Spinal loads after osteoporotic vertebral fractures treated by vertebroplasty or ky- phoplasty. Eur Spine J 2006; 15:1255-1264.

66. Belkoff SM, Mathis JM, Jasper LE, Deramond $\mathrm{H}$. An ex vivo biomechanical evaluation of a hydroxyapatite cement for use with vertebroplasty. Spine (Phila Pa 1976) 2001; 26:1542-1546.

67. Furtado N, Oakland RJ, Wilcox RK, Hall RM. A biomechanical investigation of vertebroplasty in osteoporotic compression fractures and in prophylactic vertebral reinforcement. Spine (Phila Pa 1976) 2007; 32:E480-E487.

68. Kim SH, Kang HS, Choi JA, Ahn JM. Risk factors of new compression fractures in adjacent vertebrae after percutaneous vertebroplasty. Acta Radiol 2004; 45:440-445.

69. Oakland RJ, Furtado NR, Wilcox RK, Timothy J, Hall RM. The biomechanical effectiveness of prophylactic vertebroplasty: A dynamic cadaveric study. J Neurosurg Spine 2008; 8:442-449.

70. Villarraga ML, Bellezza AJ, Harrigan TP, Cripton PA, Kurtz SM, Edidin AA. The biomechanical effects of kyphoplasty on treated and adjacent nontreated vertebral bodies. J Spinal Disord Tech 2005;
18:84-91.

71. Hadley C, Awan OA, Zoarski GH. Biomechanics of vertebral bone augmentation. Neuroimaging Clin N Am 2010; 20:159-167.

72. Disch AC, Schmoelz W. Cement augmentation in a thoracolumbar fracture model: Reduction and stability after balloon kyphoplasty versus vertebral body stenting. Spine (Phila Pa 1976) 2014; 39:E1147-E1153.

73. Kim JM, Shin DA, Byun DH, Kim HS, Kim S, Kim HI. Effect of bone cement volume and stiffness on occurrences of adjacent vertebral fractures after vertebroplasty. J Korean Neurosurg Soc 2012; 52:435-440.

74. Lin EP, Ekholm S, Hiwatashi A, Westesson PL. Vertebroplasty: Cement leakage into the disc increases the risk of new fracture of adjacent vertebral body. AJNR 2004; 25:175-180.

75. Docampo E, Ciria M, Serra-Burges J, Blanch J, Perez EL, Carbonell J. [Risk factors of new fractures after vertebroplasty]. Med Clin (Barc) 2009; 133:17-19. 